\title{
A variação da lateral pós-vocálica <l> na escrita de alunos: a posição da sílaba e a vogal precedente ${ }^{1}$
}

\author{
The variation of the post-vowel lateral $<1>$ in the \\ writing of students: the position of the syllable and the \\ preceding vowel
}

\section{La variación de la escritura de la lateral post-vocal $<\mid>$ de los estudiantes: la posición de la sílaba y la vocal precedente}

\author{
(iD) Laiane Thaís de Oliveira Silva \\ Colégio Super Aprovado (CSA), Riachão do Jacuípe, Brasil \\ E-mail: anneoliveiralk@hotmail.com \\ iD (9) Josane Moreira de Oliveira \\ Universidade Estadual de Feira de Santana (UEFS) / Universidade Federal da Bahia \\ (UFBA), Feira de Santana / Salvador, Brasil \\ E-mail: josanemoreira@hotmail.com
}

\begin{abstract}
Resumo: Analisa-se a variação da escrita da lateral pós-vocálica <1> por alunos do $3^{\circ}$ e do $5^{\circ}$ anos de duas escolas de Riachão do Jacuípe-BA. Foram documentadas as variantes $\langle\mathrm{u}\rangle \mathrm{e}\langle 0\rangle$, o rótico $\langle\mathrm{r}\rangle$, o apagamento e a manutenção do <l>. São analisadas, de acordo com os pressupostos teórico-metodológicos da Sociolinguística Variacionista, duas variáveis que influenciam a representação escrita dessa consoante: a posição da sílaba e a vogal precedente. Os resultados atestam que alunos em processo de aquisição da escrita, por não dominarem completamente as normas ortográficas, transpõem a fala para a escrita.
\end{abstract}

Palavras-chave: Lateral pós-vocálica <1>. Sociolinguística. Escrita escolar.

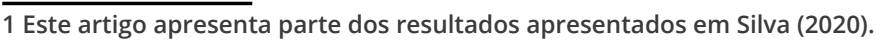


Abstract: We analyze the variation of the post-vowel lateral $<\mid>$ in the writing of students from the 3rd and 5th levels of two schools in Riachão do Jacuípe-BA. We documented the $\langle\mathrm{u}>$ and $<0>$ variants, the rotic $<r>$, the deletion and maintenance of \langle|$>$. Two variables that influence the written representation of this consonant are analyzed, according to the theoretical-methodological assumptions of Variationist Sociolinguistics: the position of the syllable and the preceding vowel. The results attest that students in the process of acquiring writing, because they do not completely master the orthographic norms, transpose speech to writing.

Keywords: Post-vowel lateral $<\mid>$. Sociolinguistics. School writing.

Resumen: Se analiza la variación de la escritura de la lateral postvocal $<>$ por estudiantes de $3^{\circ}$ y $5^{\circ}$ años de dos escuelas de Riachão do Jacuípe-BA. Se han documentado las variantes $\langle u\rangle$ y $\langle 0\rangle$, el rotic $<r>$, la eliminación y el mantenimiento de $<1>$. Se analizan dos variables que influyen en la representación escrita de esta consonante, según los supuestos teórico-metodológicos de la Sociolingüística Variacionista: la posición de la sílaba y la vocal precedente. Los resultados atestiguan que los estudiantes en el proceso de adquirir la escritura, debido a que no dominan completamente las normas ortográficas, trasponen el habla a la escritura.

Palabras clave: Post-vocal lateral <|>. Sociolingüística. Escritura escolar.

Submetido em 15 de fevereiro de 2021.

Aceito em 10 de abril de 2021.

Publicado em 01 de novembro de 2021. 
A variação da lateral pós-vocálica <।> na escrita de alunos: a posição da sílaba e a vogal precedente Laiane Thaís de Oliveira Silva • Josane Moreira de Oliveira

\section{Introdução}

O fonema lateral ///, objeto de estudo neste artigo em sua representação escrita, apresenta diferentes realizações fonéticas a depender de sua posição na sílaba. Em palavras como lobo e lama, por exemplo, em que a lateral antecede a vogal (posição pré-vocálica), é caracterizada como dento-alveolar [l]; quando aparece depois de uma vogal (posição pós-vocálica), como em mel, anzol e alma, pode ser realizada com uma articulação alveolar [l], velar [t] ou como semivogal posterior [W], fone que predomina no português brasileiro (cf. CRISTÓFARO SILVA, 1999). Ainda nesta última posição, pode sofrer apagamento e não ser pronunciada, como em [pa'pe], e pode também ser realizada como /R/ (arquifonema que tem diferentes realizações fonéticas), como em /'aRma/ e /pa'peR/. O fonema /// pode aparecer também como segundo elemento de um grupo consonantal, como em planta e atlas, cuja realização pode ser dento-alveolar ou ainda vibrante - esta última articulação conhecida como resultado do processo chamado de rotacismo.

Diante das diferentes realizações do fonema /l/, é possível perceber que há maior variação quando ele se encontra em posição pós-vocálica. Essa variação que ocorre na fala pode ser observada também na escrita de alunos em processo de aquisição das normas ortográficas, ou até mesmo na escrita de pessoas adultas que não possuem o domínio dessas convenções, que comumente transferem fenômenos fonéticos para a escrita.

O foco deste artigo é justamente essa variação na escrita de alunos do $3^{\circ}$ e do $5^{\circ}$ anos do nível fundamental, de duas escolas do município de Riachão do Jacuípe-BA. Procura-se identificar as variantes utilizadas na representação gráfica do fonema /l/ em posição pós-vocálica, verificando a atuação de duas variáveis na escolha de cada variante por parte dos alunos: a 'posição da sílaba' e a 'vogal precedente'. 
A variação da lateral pós-vocálica <।> na escrita de alunos: a posição da sílaba e a vogal precedente Laiane Thaís de Oliveira Silva • Josane Moreira de Oliveira

\section{Aporte teórico}

Tomando por base teórico-metodológica a Sociolinguística Variacionista (WEINREICH; LABOV; HERZOG, 2006 [1968]; LABOV, 2008 [1972]) para a análise do fenômeno variável escolhido, objetiva-se investigar neste artigo: (a) quais as variantes utilizadas pelos alunos na representação gráfica do fonema /l/ em posição pós-vocálica; (b) quais variáveis se mostram relevantes para a variação estudada.

\section{Sociolinguística Variacionista}

A Sociolinguística Variacionista, também conhecida como Sociolinguística Laboviana, Sociolinguística Quantitativa ou ainda como Teoria da Variação e Mudança, é uma área da linguística que estuda a relação entre língua e sociedade e tem como seu principal precursor o linguista norte-americano William Labov. Contrário às teorias que privilegiam apenas as forças internas para analisar a propagação e a regularização das mudanças linguísticas, Labov (2008 [1972]) considera que:

[...] uma abordagem que considera apenas as pressões estruturais dificilmente pode contar a história toda. Nem todas as mudanças são altamente estruturadas, e nenhuma mudança acontece num vácuo social. Até mesmo a mudança em cadeia mais sistemática ocorre num tempo e num lugar específicos, o que exige uma explicação (LABOV, 2008 [1972], p. 20).

Em seus estudos sobre a variação dos ditongos /ay/ e /aw/ na ilha de Martha's Vineyard (tema de sua dissertação de Mestrado) e sobre a estratificação do inglês em Nova York (tema de sua tese de Doutorado), William Labov procurou investigar qual era a motivação social das mudanças sonoras. As suas descobertas através dessas pesquisas permitiram a postulação de vários princípios so- 
A variação da lateral pós-vocálica <|> na escrita de alunos: a posição da sílaba e a vogal precedente Laiane Thaís de Oliveira Silva • Josane Moreira de Oliveira

ciolinguísticos que explicam a mudança linguística (LABOV, 2008 [1972]), como, por exemplo, os fatores condicionadores e o encaixamento social da mudança.

Contrários às teorias de base estruturalista e gerativista, que, em suma, pregavam, respectivamente, uma visão de língua como estrutura autônoma e homogênea, e uma concepção de língua como sistema abstrato de regras desvinculado de fatores externos, Weinreich, Labov e Herzog (2006 [1968]) lançam os fundamentos empíricos para uma teoria da mudança linguística, partindo do pressuposto de que a língua é um sistema inerentemente heterogêneo e ordenado.

Nos parece bastante inútil construir uma teoria da mudança que aceite como seu input descrições desnecessariamente idealizadas e inautênticas dos estados de língua. Muito antes de se poder esboçar teorias preditivas da mudança linguística, será necessário aprender a ver a língua - seja de um ponto de vista diacrônico ou sincrônico - como um objeto constituído de heterogeneidade ordenada (WEINREICH; LABOV; HERZOG, 2006 [1968], p. 35).

Para Weinreich, Labov e Herzog (2006 [1968]), os fatos da heterogeneidade nunca se adequaram muito bem à abordagem estrutural da língua, pois a estruturação - que tanto impressiona os linguistas e os faz se apoiar em observações de caráter dedutivo para explicar as vantagens funcionais dessa estrutura - esbarra no mistério da transição de uma língua de um estado para outro. A esse respeito, os autores levantam a seguinte questão: "Afinal, se uma língua tem de ser estruturada, a fim de funcionar eficientemente, como é que as pessoas continuam a falar enquanto a língua muda, isto é, enquanto passa por períodos de menor sistematicidade?" (WEINREICH; LABOV; HERZOG, 2006 [1968], p. 35).

Em outras palavras, se a língua passa por um processo de mudança, em que, consequentemente, sua estrutura fica seriamen- 
A variação da lateral pós-vocálica <।> na escrita de alunos: a posição da sílaba e a vogal precedente Laiane Thaís de Oliveira Silva • Josane Moreira de Oliveira

te comprometida? Como os falantes conseguem se entender durante esse processo? A solução para tal questão, de acordo com os autores, está no rompimento do reconhecimento da estruturalidade como homogeneidade. Para Weinreich, Labov e Herzog (2006 [1968]), um falante nativo tem domínio sobre estruturas heterogêneas e isso nada tem a ver com multidialetalismo ou com o simples desempenho; pelo contrário, esse domínio faz parte de sua competência linguística monolíngue. Ou seja, num processo de mudança linguística, um falante dispõe em seu repertório linguístico de formas distintas que expressam o mesmo significado, o que constitui a variação linguística. À medida que uma forma vai perdendo força no sentido de prática de uso e deixa de ser usada dando espaço para a nova forma, tem-se o processo de mudança linguística.

Portanto, para esses autores, a língua continua estruturada enquanto as mudanças acontecem, o que permite que os falantes continuem a se comunicar durante o processo de mudança. Dessa forma, os autores negam a condição de estruturação atrelada ao conceito de homogeneidade ao considerarem que a língua é estruturada e heterogênea, e afirmam ainda que, "numa língua que serve a uma comunidade complexa (i.e., real), a ausência de heterogeneidade estruturada é que seria disfuncional" (WEINREICH; LABOV; HERZOG, 2006 [1968], p. 36).

\section{A variação linguística e o ensino de língua materna}

O Brasil é um país de dimensões continentais. Por isso, em razão de sua grandeza, possui uma ampla diversidade que se manifesta em diferentes aspectos: diversidade ambiental, diversidade climática, diversidade cultural, diversidade linguística, entre outras. Enquanto algumas manifestações dessa diversidade são bem compreendidas e até mesmo valorizadas e preservadas, como, por exemplo, as manifestações folclóricas, a diversidade linguís- 
A variação da lateral pós-vocálica <|> na escrita de alunos: a posição da sílaba e a vogal precedente Laiane Thaís de Oliveira Silva • Josane Moreira de Oliveira

tica é, muitas vezes, palco de crenças e julgamentos repletos de preconceito.

Outro impasse a respeito da diversidade linguística se refere à forma como a escola lida com a mesma. Com a democratização do ensino no nosso país, a escola passou a receber alunos de diferentes esferas sociais e advindos também de diferentes regiões brasileiras. Como então a escola, à qual sempre coube o papel de preservação da "boa" linguagem, deve encarar essa realidade plural e oferecer, de forma igualitária aos alunos, o saber necessário para que se cumpra o que estabelecem as orientações oficiais para a educação no nosso país? É sobre esse grande desafio que se discorre a seguir. Primeiramente, considera-se pertinente abordar o que propõem os Parâmetros Curriculares Nacionais (PCN) para o ensino de Língua Portuguesa nas séries iniciais. A variação linguística é abordada em tais parâmetros a partir da seguinte perspectiva:

A Língua Portuguesa, no Brasil, possui muitas variedades dialetais. Identificam-se geográfica e socialmente as pessoas pela forma como falam. Mas há muitos preconceitos decorrentes do valor social relativo que é atribuído aos diferentes modos de falar: é muito comum se considerarem as variedades linguísticas de menor prestígio como inferiores ou erradas (BRASIL, 1997, p. 26).

Como se observa, existe nas orientações oficiais o reconhecimento das diferenças dialetais da língua portuguesa no Brasil. Tal constatação vem acompanhada da necessidade de realizar um trabalho com a língua portuguesa que vise ao enfrentamento do problema referente ao preconceito linguístico. Ao orientar que "para poder ensinar Língua Portuguesa, a escola precisa livrar-se de alguns mitos: o de que existe uma única forma 'certa' de falar" (BRASIL, 1997, p. 26), os PCN reforçam tal enfrentamento. Dentre os objetivos propostos pelos PCN para o ensino de Língua Portuguesa, que embasam tal posicionamento, estão: 
A variação da lateral pós-vocálica <।> na escrita de alunos: a posição da sílaba e a vogal precedente Laiane Thaís de Oliveira Silva • Josane Moreira de Oliveira

- Utilizar diferentes registros, inclusive os mais formais da variedade linguística valorizada socialmente, sabendo adequá-los às circunstâncias da situação comunicativa de que participam;

- Conhecer e respeitar as diferentes variedades linguísticas do português falado;

- Conhecer e analisar criticamente os usos da língua como veículo de valores e preconceitos de classe, credo, gênero ou etnia (BRASIL, 1997, p. 33).

A partir de tais fragmentos, pode-se constatar que o trabalho do professor de Língua Portuguesa, que vise ao respeito aos diferentes falares dos alunos que frequentam a escola, está amplamente preconizado por tais diretrizes. No entanto, o que se percebe na prática escolar é uma postura contrária ao que se espera em relação ao tratamento da variação linguística por parte de alguns profissionais da educação.

Bortoni-Ricardo (2004) aponta para o fato de que as variedades linguísticas se justapõem na sala de aula justamente no momento em que o aluno utiliza uma regra não padrão e o professor intervém, apresentando a norma padrão. É justamente essa atitude - a de como proceder nesse momento - que ainda gera dúvida em muitos profissionais.

A autora considera que os educadores brasileiros, com destaque para os linguistas, têm feito um trabalho muito importante ao mostrar que é pedagogicamente incorreto utilizar a incidência de uma regra não padrão pelo aluno como uma oportunidade para humilhá-lo. Assim, é necessário que se atente para as diferenças que envolvem a cultura dos alunos e a da escola para que o professor encontre formas efetivas de conscientizar os educandos sobre tais diferenças. No entanto, na prática, continua a autora, esse é um comportamento que ainda gera problemas para os professores, que ficam inseguros, sem saber se devem corrigir ou não, que erros devem corrigir e ainda se podem ou não falar em erros. As dúvidas e inseguranças que permeiam a prática de alguns pro- 
A variação da lateral pós-vocálica <।> na escrita de alunos: a posição da sílaba e a vogal precedente Laiane Thaís de Oliveira Silva • Josane Moreira de Oliveira

fissionais da educação, em especial a de professores de Língua Portuguesa, provêm justamente do conflito que se instaura entre a norma (prevista) e a variação (manifesta).

Há ainda outro agravante para esse desconforto entre os professores: a não consideração das diferenças entre as modalidades falada e escrita da língua - a primeira variável e a segunda invariável, normatizada, padronizada. E isso se apresenta exatamente na aquisição da língua escrita, que muitas vezes apresenta reflexos da oralidade, que é, por natureza, bastante diversificada.

\subsection{Contribuições da sociolinguística para o ensino}

A abordagem da variação linguística na prática do professor de língua materna é de grande importância a fim de que haja discussões relacionadas à construção de julgamentos de valor pelo falante a respeito de sua própria língua.

De acordo com Cyranka (2014), um dos grandes problemas enfrentados pela escola para atingir o principal objetivo do ensino de língua portuguesa - o de propiciar aos alunos o desenvolvimento da competência da leitura e da escrita nas variedades cultas da língua - decorre da carência de uma pedagogia adequada para tal. Segundo a autora, essa carência acaba por resultar em atitudes negativas dos alunos em relação à própria competência para aprender as variedades de maior prestígio, um problema ligado à avaliação que os alunos fazem da variedade linguística que utilizam. Daí as crenças e atitudes negativas ou equivocadas sobre o que é a língua, sobre qual é a língua "correta". Daí também decorre o fato de a língua ser considerada "difícil". E essa ideologia advém de vários fatores: da tradição do ensino baseado na gramática normativa, da falta de uma formação sociolinguística do professor, do tabu social sobre (in)correção linguística, da experiência/história de vida do aluno. A esse respeito a autora considera que: 
A variação da lateral pós-vocálica <।> na escrita de alunos: a posição da sílaba e a vogal precedente Laiane Thaís de Oliveira Silva • Josane Moreira de Oliveira

As crenças dos alunos sobre a língua que falam e sobre a que a escola lhes quer ensinar são construídas ao longo do processo de ensino/aprendizagem, a partir do que lhes é oferecido nesse ambiente, somado, evidentemente, às suas experiências fora da escola (CYRANKA, 2014, p. 144).

A atitude do professor frente a tal questão é, portanto, de suma importância no desencadear de tais avaliações. Para Cyranka (2014), é das crenças que nascem as atitudes e é através do levantamento de um conjunto de crenças dos professores e dos alunos com relação a questões relacionadas à língua, à linguagem, à variação e à aprendizagem linguística que se pode obter um sistema de crenças que explique as atitudes dos professores em relação à variedade linguística de seus alunos e, consequentemente, a atitude desses alunos com relação ao próprio desempenho linguístico.

Considerando o problema das relações de poder na sociedade, que não pode ser negado, entende-se que a escola, se não pode diretamente mudar as bases de dominação, constitui-se num mecanismo na luta pela mudança social. A parte que lhe cabe nessa luta é, portanto, a de proporcionar um ensino eficaz que permita àqueles que não dispõem de privilégios sociais o acesso a lugares de prestígio. Esse processo, sem sombra de dúvidas, perpassa pelo uso que se faz da linguagem e, por isso, cabe à escola dar um tratamento adequado a ela, seja na luta pela erradicação do preconceito linguístico, através da avaliação dos diferentes dialetos, seja no oferecimento das variedades cultas da língua como instrumento de acesso à informação e a bens culturais, veiculados nessas normas e de domínio de apenas uma parte da sociedade.

O respeito às diferentes variedades linguísticas, já previsto nos PCN, no entanto, depende antes de mais nada do conhecimento por parte dos alunos do quadro de variação linguística existente no nosso país. A esse respeito, Coelho et al. (2015) consideram que, a partir de reflexões sobre as regras variáveis da língua e dos valores sociais que são atribuídos a cada variedade, é possível que se diferenciem as variedades e os efeitos sociais decorrentes de 
A variação da lateral pós-vocálica <|> na escrita de alunos: a posição da sílaba e a vogal precedente Laiane Thaís de Oliveira Silva • Josane Moreira de Oliveira

seus usos. Segundo os autores, o ensino da norma culta nas escolas deve suceder esse estudo comparativo das variedades linguísticas e das implicações referentes ao uso destas. Tal abordagem também se faz importante no trabalho de ensino-aprendizagem da escrita:

Acreditamos que uma reflexão sobre a heterogeneidade da modalidade falada torna-se crucial, especialmente quando os alunos começam a conviver com a modalidade escrita. Os pontos de contraste entre as variedades coexistentes devem ser apontados, descritos e discutidos pela escola, para que o aluno tenha conhecimento dos fenômenos variáveis, das regras linguísticas que regem a variação e dos preconceitos relativos ao uso da língua (COELHO et al., 2015, p. 142).

Uma abordagem sociolinguística desde os primeiros anos da vida escolar, segundo Cyranka (2014, p. 150), é muito produtiva "para os alunos irem se assegurando de que, em linguagem, diferença não constitui deficiência". Para isso, fica evidente a importância da formação do professor, que precisa ter um embasamento teórico consistente a respeito do funcionamento da linguagem e sua função social, para poder atuar de forma competente na formação do aluno, enfatizando a questão da heterogeneidade linguística, a fim de combater preconceitos e avaliações errôneas sobre a língua.

A respeito da contribuição da sociolinguística para o ensino de língua, pode-se afirmar que uma formação sociolinguística do professor é de fundamental importância, pois é sua responsabilidade orientar os alunos a respeito das crenças e atitudes linguísticas, enfatizando a importância e a funcionalidade de cada variedade da língua, inclusive das formas vernaculares. O reconhecimento do valor das formas linguísticas utilizadas pelos alunos amplia sua capacidade de recepção de outras variedades, incluindo as de maior prestígio social. É papel da escola promover o acesso às normas de prestígio, cuja aquisição é um meio de possibilitar aos alu- 
A variação da lateral pós-vocálica <।> na escrita de alunos: a posição da sílaba e a vogal precedente Laiane Thaís de Oliveira Silva • Josane Moreira de Oliveira

nos acesso a lugares sociais privilegiados e assim contribuir com a luta pela mudança social, pois que a linguagem é, sim, um meio de dominação e de discriminação, mas também é uma importante arma social.

Tendo consciência da diversidade linguística, alunos e professores podem ser reflexivos sobre as diferenças entre fala e escrita, por exemplo. Assim, ao trabalhar com ortografia, é preciso que entendam que não há uma relação biunívoca entre sons e letras. Ao grafar o fonema /// com $<\mathrm{u}>^{2}$ ou com <r> (papeu ou paper), o aluno transfere a sua oralidade para a escrita. Certamente isso não acontece quando esse fonema aparece em posição pré-vocálica (lata). Assim, identificados os contextos e comparando fala e escrita, o processo de ensino-aprendizagem da ortografia se torna mais produtivo. O professor precisa, observando a escrita do aluno, traçar um diagnóstico, identificar o tipo de erro - se decorrente de interferência da fala, se decorrente do desconhecimento de regras, se decorrente da arbitrariedade do sistema - para então elaborar uma proposta metodológica (cf. BORTONI-RICARDO, 2004).

Sendo a aquisição da escrita um processo contínuo, o que se espera é que, à medida que o aluno avance em sua escolarização, domine mais a ortografia e cometa menos erros.

\section{Procedimentos metodológicos}

O corpus da pesquisa é constituído por uma amostra composta de exercícios respondidos por alunos do $3^{\circ}$ e do $5^{\circ}$ anos do Ensino Fundamental de duas escolas da cidade de Riachão do Jacuípe, na Bahia: uma escola da rede pública e outra da rede particular de ensino. Os dados foram coletados em 2018.

Optou-se por essas séries pelo fato de elas constituírem, respectivamente, uma etapa inicial ( $3^{\circ}$ ano) e a etapa final ( $5^{\circ}$ ano) do Ensino Fundamental I e, desse modo, verificar o aprendizado

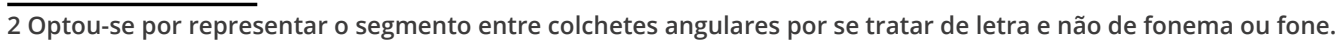


A variação da lateral pós-vocálica <।> na escrita de alunos: a posição da sílaba e a vogal precedente Laiane Thaís de Oliveira Silva • Josane Moreira de Oliveira

dos alunos à medida que avançam em sua escolarização. Já quanto ao tipo de escola (pública ou particular), objetivou-se averiguar se as diferenças socioeconômicas dos alunos interferem em suas formas de escrita, já que são escolas cujos alunos pertencem a classes sociais diferentes. Tanto a série/ano escolar quanto o tipo de escola são variáveis que atuam na opção de escrita de <1> (cf. SILVA, 2020), mas essas varáveis não são objeto deste artigo, que apresenta apenas as variáveis 'posição da sílaba' e 'vogal precedente'.

O exercício utilizado na coleta de dados foi elaborado para a pesquisa, contém três questões e foi aplicado a todos os alunos das duas séries das duas escolas. Na primeira questão foi utilizada a técnica proposta por Tasca (2006), chamada teste de lacuna, que consiste em solicitar aos alunos que escrevam o nome de cada figura que aparece no exercício. Nessa primeira questão, a maioria dos nomes das figuras escolhidas apresenta a lateral $<\mid>$ em final de sílaba, tanto em posição medial como em posição final. Não foram colocadas apenas palavras com essa característica a fim de que os alunos não atentassem para o que estava sendo investigado e, assim, fosse possível coletar a escrita mais espontânea possível dos alunos. As palavras selecionadas para essa primeira questão e que apresentam a lateral /// em posição pós-vocálica foram: sol, bombril, caracol, almofada, barril, soldado, papel, polvo, avental, golfinho, pulseira, balde, filtro, poltrona, pastel, funil, anel, vulcão, jornal, varal, calça e farol.

A segunda questão proposta no exercício apresenta perguntas diretas de conhecimento geral e em conformidade com o nível de escolarização dos alunos também se optou nessa questão por não colocar apenas palavras com a lateral $<1>$ em final de sílaba pelo motivo já mencionado anteriormente. A fim de evitar perda de dados, foi sinalizada a primeira letra de cada resposta para as perguntas feitas nessa questão, como nos seguintes exemplos: a) O nome do nosso país é $\boldsymbol{B} \_$_ b) O instrumento utilizado na pesca para colocar a isca é o $\boldsymbol{a}$ ; Meio-dia é a hora do $\boldsymbol{a}$ As respostas para as perguntas e cujas palavras apresentam o fe- 
A variação da lateral pós-vocálica <|> na escrita de alunos: a posição da sílaba e a vogal precedente Laiane Thaís de Oliveira Silva • Josane Moreira de Oliveira

nômeno aqui investigado foram: Brasil, anzol, azul, canil, multiplicação, selvagem, último, almoço, sul, Sílvio, filme, selva, Celso e abril.

Por fim, na última questão, foi solicitado que os alunos escrevessem uma narrativa. Foi contado para as turmas participantes da pesquisa o início de uma história ("Vai ter festa na selva!!!!", de Minéia Pacheco) e foi proposto que os alunos escrevessem uma continuação e um final para a mesma. São exemplos de palavras documentadas na escrita livre: selva, animal, local, final, mel, moral, hospital, totalmente, último, algum. O objetivo com essa questão era verificar se havia relação entre a forma de escrita (livre, na terceira questão; ou direcionada, nas duas anteriores) e o uso das variantes para representar o fonema <1>. Contudo essa variável (tipo de escrita) não é objeto deste artigo.

A amostra da pesquisa é então constituída por 77 exercícios. Desse total, 16 exercícios são de alunos do $3^{\circ}$ ano do Ensino Fundamental da escola da rede pública, 18 são de alunos do $5^{\circ}$ ano do Ensino Fundamental dessa mesma instituição, 19 são de alunos do $3^{\circ}$ ano do Ensino Fundamental da escola particular e 24 são de alunos do $5^{\circ}$ ano dessa mesma instituição. Os números de exercícios por turma variam conforme o número de alunos que estavam presentes no dia da aplicação do instrumento e cujos pais ou responsáveis assinaram o Termo de Consentimento Livre e Esclarecido $(\mathrm{TCLE})^{3}$.

Após coletados, os dados foram codificados e processados no Programa GoldVarb X4 (SANKOFF; TAGLIAMONTE; SMITH, 2005) para a realização dos cálculos estatísticos, cujos resultados se apresentam na próxima seção.

3 Como a pesquisa envolveu seres humanos, o projeto foi submetido e aprovado pelo Comitê de Ética em Pesquisa da Universidade Universidade Estadual de Feira de Santana (Processo número 93507818.6.0000.0053).

4 Programa computacional que realiza cálculos estatísticos e probabilísticos utilizado em pesquisas sociolinguísticas para a análise de regras variáveis. O programa recebe os dados codificados segundo as variáveis estabelecidas e gera as frequências e os pesos relativos de cada fator considerado. Atestando a relevância estatística das variáveis e sua ordem de importância, são atribuídos pesos relativos, que variam entre 0 e 1, e indicam a probabilidade de aplicação da regra. Assim, quanto mais próximo de 1, maior a probabilidade de aplicação; quanto mais próximo de 0 , menor a probabilidade de que a regra se aplique. 
A variação da lateral pós-vocálica <|> na escrita de alunos: a posição da sílaba e a vogal precedente Laiane Thaís de Oliveira Silva • Josane Moreira de Oliveira

\section{Discussão dos resultados}

A hipótese norteadora da pesquisa foi a de que haveria variação na escrita escolar do fonema /l/, por interferência da fala. Como previsto, a variante padrão, representada pela escrita da lateral $<1>$, não foi a única utilizada pelos alunos envolvidos na pesquisa. Além desta, foram encontradas outras variantes, apresentadas na Tabela 1, a seguir:

Tabela 1: Distribuição geral das ocorrências

\begin{tabular}{l|c|c}
\hline \multicolumn{1}{c|}{ Variantes } & Ocorrências & Percentual \\
\hline Lateral $<$ > $>$ & 1897 & $69,6 \%$ \\
\hline Apagamento & 370 & $13,6 \%$ \\
\hline Vocalização5 $<$ u> & 339 & $12,4 \%$ \\
\hline Vocalização $<0>$ & 114 & $4,2 \%$ \\
\hline Rótico $<r>$ & 5 & $0,2 \%$ \\
\hline Total & 2725 & $100 \%$ \\
\hline
\end{tabular}

Fonte: Silva (2020, p. 88).

Como se observa na Tabela 1, das 2725 ocorrências encontradas, 1897 correspondem à escrita da lateral (I), totalizando 69,6\% dos casos; 370 foram do apagamento (2), totalizando 13,6\% dos casos; 339 foram da vocalização com <u> (3), totalizando 12,4\% dos casos; 114 foram da vocalização com <0> (4), totalizando 4,2\% dos casos; e 5 foram do uso do rótico $<r>(5)$, totalizando apenas $0,2 \%$ dos dados.
(1) pastel ('pastel')
(2) faro ('farol')
(3) caniu ('canil')
(4) abrio ('abril')
(5) caracor ('caracol')

50 termo vocalização foi adotado aqui para a representação escrita do fonema /l/ com as letras $\langle\mathrm{u}\rangle \mathrm{e}\langle 0\rangle$, que ilustram a vocalização do /l/ como [w] (cf. BORTONI-RICARDO, 2004). 
A variação da lateral pós-vocálica <।> na escrita de alunos: a posição da sílaba e a vogal precedente Laiane Thaís de Oliveira Silva • Josane Moreira de Oliveira

Como apresentado na Tabela 1, a variante padrão é a forma mais utilizada pelos alunos, apesar de ser a forma vocalizada do /I/ em final de sílaba a realizada pelos alunos em sua fala. Com base nas séries escolares escolhidas para a pesquisa, entende-se que os alunos já possuem o conhecimento de que não existe uma relação biunívoca entre sons e letras. No entanto, como se observa, a variante padrão não foi a única utilizada. Os dados de apagamento mostram ser este um recurso bastante utilizado pelos alunos, ocupando a segunda posição em termos de frequência de uso. Os dados referentes à vocalização demonstram a interferência da oralidade na escrita e ainda apontam para um caso de hipercorreção, devido, justamente, à noção que os alunos já possuem de que, na escrita, um som pode ser representado por mais de uma letra.

A seguir são apresentados os resultados encontrados nas rodadas binárias obtidas a partir do GoldVarb X (SANKOFF; TAGLIAMONTE; SMITH, 2005), estando juntos todos os dados coletados nas duas séries e nas duas escolas. A regra de aplicação é sempre a forma não padrão de escrita (em oposição à lateral <|>, variante padrão), pois o objetivo é verificar o contexto que favorece as escritas alternativas. Neste artigo, são apresentados apenas os resultados referentes ao apagamento da lateral e à vocalização com $\langle u>$, segunda e terceira opções, respectivamente, mais usadas pelos alunos. Primeiramente, são apresentados os resultados de apagamento da lateral e, em seguida, os resultados de vocalização com $<u>$, levando em consideração a atuação das variáveis linguísicas 'posição da sílaba' e 'vogal precedente'. A análise das demais variantes (vocalização com $<0>$ e rótico $<r>$ ) e a atuação das demais variáveis ('tipo de escola', 'ano escolar' e 'tipo de escrita) podem ser encontradas em Silva (2020).

\subsection{Posição da sílaba nos casos de apagamento da lateral $<1>$}

A partir do levantamento das ocorrências, buscou-se verificar se a localização da sílaba com a lateral pós-vocálica na palavra era 
A variação da lateral pós-vocálica <।> na escrita de alunos: a posição da sílaba e a vogal precedente Laiane Thaís de Oliveira Silva • Josane Moreira de Oliveira

condicionante da sua representação escrita. Assim, consideraram-se as seguintes posições como fatores: sílaba inicial (poltrona, almoço), sílaba medial (resolveu, acalmar) e sílaba final (farol, canil). Foram isolados os vocábulos monossilábicos (sol, sul), pois, devido à extensão da palavra, assumiu-se a hipótese de que estas seriam menos passíveis de sofrer variação e poderiam enviesar os resultados.

Foram atestadas como posições da sílaba favorecedoras do apagamento da lateral a posição medial e a posição inicial, como apresentado na Tabela 2.

Tabela 2: Apagamento e 'Posição da sílaba'

\begin{tabular}{l|c|c|c}
\hline \multicolumn{1}{c|}{ Posição da sílaba } & Ocorrências/total & Percentual & Peso relativo \\
\hline Inicial & $321 / 1127$ & $28,5 \%$ & $\mathbf{0 , 8 1 4}$ \\
\hline Medial6 & $8 / 12$ & $66,7 \%$ & $\mathbf{0 , 9 4 7}$ \\
\hline Final & $30 / 965$ & $3,1 \%$ & 0,190 \\
\hline Monossílabo & $11 / 163$ & $6,7 \%$ & 0,140 \\
\hline
\end{tabular}

Input: 0,036 Significância: 0,000

Fonte: Silva (2020, p. 112).

A sílaba em posição medial apresenta peso relativo de 0,947, mostrando ser esta posição a que mais favorece o apagamento da lateral. A posição inicial também é contexto favorecedor do apagamento, com peso relativo de 0,814. Já a posição final inibe o apagamento, com peso relativo de 0,190, assim como os monossílabos, com peso relativo de 0,140. Acredita-se que não é comum aos alunos envolvidos na pesquisa a pronúncia de formas como [pa'pc] (papel), [a'nc] (anel), ['so] (sol). Dessa forma, confirma-se a hipótese de que o apagamento do <1> seja favorecido em sílaba interna de palavra (inicial e medial) e inibida em sílaba final absoluta, embora tenha sido documentado em 41 dados (11 em monossílabos e 30 em outras palavras).

6 Os vocábulos referentes ao contexto medial só foram encontrados na escrita livre, o que explica o número pequeno de ocorrências. 
A variação da lateral pós-vocálica <।> na escrita de alunos: a posição da sílaba e a vogal precedente Laiane Thaís de Oliveira Silva • Josane Moreira de Oliveira

Seguem exemplos de dados encontrados no corpus que ilustram o apagamento da lateral <l> em todas as sílabas controladas:

Em sílaba inicial:

(6) útimo ('último')

Em sílaba medial:

(7) resoveu ('resolveu')

Em sílaba final:

(8) faro ('farol')

Em monossílabo:

(9) sú ('sul')

É interessante notar que em (9) o aluno apagou a lateral, mas colocou acento agudo na palavra, representando o seu alongamento na fala.

\subsection{Vogal precedente nos casos de apagamento da lateral $<\mid>$}

Esta variável mostra-se relevante na observação da variação da escrita da lateral \langle|$>$, que se apresenta de maneiras distintas a depender da vogal precedente. Para esta observação, foi considerada a altura da língua ao se pronunciar a vogal, que, nas palavras de Silva (2001, p. 66), "refere-se à altura ocupada pelo corpo da língua durante a articulação do segmento vocálico". Segundo a autora, essa altura representa verticalmente a dimensão que é ocupada pela língua dentro da cavidade bucal. É possível observar essas diferenças de alturas ao se pronunciar em sequência as vogais /i/ e /a/. A posição da língua localiza-se mais alta durante a pronúncia da vogal /i/ e mais baixa durante a pronúncia da vogal /a/. Na descrição do português, são considerados quatro níveis de 
A variação da lateral pós-vocálica <।> na escrita de alunos: a posição da sílaba e a vogal precedente Laiane Thaís de Oliveira Silva • Josane Moreira de Oliveira

altura vocálica: alta /i, u/, média alta /e, o/, média baixa / $\varepsilon$, o/, baixa /a/. No entanto, para a análise da variação da lateral <|> nesta pesquisa, não foi levada em consideração a distinção entre as vogais /o/ e / /, e /e/ e /ع/, pois, através dos exercícios de escrita, que compõem os dados desta pesquisa, não é possível atestar como essas vogais são pronunciadas pelos alunos em palavras como soldado e selvagem, por exemplo. Na escrita, as vogais são reduzidas a apenas cinco, anulando-se a distinção de altura entre as médias.

Com relação ao comportamento da lateral após a vogal alta /u/, pela semelhança fônica entre a vogal e a semivogal [w] (realização majoritária do fonema /// na comunidade estudada e no Brasil), esperava-se que fosse apagada a representação de <|>, pois não seriam aceitas na forma escrita da nossa língua formações do tipo suu/azuu. Essa semelhança fônica pode ainda indicar a hipótese contrária com relação ao comportamento da lateral <|>: a sua manutenção quando esta for antecedida pela vogal alta /u/.

A seguir, são apresentados os resultados para essa variável e os índices confirmam a hipótese aventada para os casos de apagamento da lateral $<\mid>$.

Tabela 3: Apagamento e 'Vogal precedente'

\begin{tabular}{c|c|c|c}
\hline Vogal precedente & Ocorrências/total & Percentual & Peso relativo \\
\hline A & $36 / 458$ & $7,9 \%$ & 0,341 \\
\hline E & $11 / 362$ & $3 \%$ & 0,127 \\
\hline I & $30 / 497$ & $6 \%$ & 0,303 \\
\hline O & $106 / 503$ & $21,1 \%$ & $\mathbf{0 , 7 2 8}$ \\
\hline U & $187 / 447$ & $41,8 \%$ & $\mathbf{0 , 8 8 6}$ \\
\hline
\end{tabular}

Input: 0,036 Significância: 0,000

Fonte: Silva (2020, p. 111).

Os resultados apresentados na Tabela 3 mostram ser a vogal precedente $<\mathrm{u}>$ a que mais favorece o apagamento da lateral $<1>$ (peso relativo de 0,886 ). Este fato deve-se justamente à semelhança fônica que existe entre o som dessa vogal e o da semivogal [w], assumido pela lateral $<1>$ em final de sílaba na oralidade dos alu- 
A variação da lateral pós-vocálica <|> na escrita de alunos: a posição da sílaba e a vogal precedente Laiane Thaís de Oliveira Silva • Josane Moreira de Oliveira

nos envolvidos na pesquisa. Como a saliência fônica entre estes dois sons é muito pouca, o aluno que não conhece a grafia correta das palavras com <l> em posição pós-vocálica tendem a apagar essa letra quando ela aparece após a vogal alta posterior $<\mathrm{u}>$.

A mesma explicação é válida para o apagamento da lateral $<\mid>$ quando a vogal precedente é $\langle 0\rangle$, também favorecedora do apagamento, como revelam os resultados (peso relativo de 0,728 ).

Já as vogais $\langle a>$, $<\mathrm{e}>\mathrm{e}<\mathrm{i}>$ inibem o apagamento, com pesos relativos de 0,341, 0,127 e 0,303, respectivamente. Assim, é mais provável que os alunos não escrevam a lateral <l> quando esta aparece em palavras como caracol e anzol do que em palavras como papel, jornal e Brasil. Não se pode descartar a hipótese de que pode atuar aí também a familiaridade ou não que os alunos têm com certas palavras, fato difícil de ser apurado.

Abaixo seguem exemplos de apagamento da lateral $<\mid>$ quando precedida por cada vogal.

Vogal precedente A:

(10) amofada ('almofada')

Vogal precedente $\mathrm{E}$ :

(11) seva ('selva')

Vogal precedente I:

(12) fitro ('filtro')

Vogal precedente O:

(13) caraco ('caracol')

Vogal precedente U:

(14) $a z u$ ('azul') 


\subsection{Posição da sílaba nos casos de vocalização com <u>}

Esta variável foi controlada com o intuito de verificar se a localização da lateral < > na estrutura da palavra se mostra ou não relevante para o uso de uma ou outra variante. Na Tabela 4 estão dispostos os resultados encontrados.

Tabela 4: Vocalização <u> e 'Posição da sílaba'

\begin{tabular}{l|c|c|c}
\hline \multicolumn{1}{c|}{ Posição da sílaba } & Ocorrências/total & Percentual & Peso relativo \\
\hline Inicial & $215 / 1021$ & $21,1 \%$ & $\mathbf{0 , 6 8 3}$ \\
\hline Medial7 & $2 / 6$ & $33,3 \%$ & $\mathbf{0 , 6 7 9}$ \\
\hline Final & $120 / 1055$ & $11,4 \%$ & 0,410 \\
\hline Monossílabo & $2 / 154$ & $1,3 \%$ & 0,068 \\
\hline
\end{tabular}

Input: 0,066 Significância: 0,007

Fonte: Silva (2020, p. 92).

Como se pode observar, a escrita da vogal <u> no lugar da consoante lateral <|> não foi recorrente em posição final de palavra, não sendo tal contexto, pois, favorável à vocalização. Os contextos que mais favorecem a grafia < u> são a posição inicial (peso relativo de 0,683 ) e a medial (peso relativo de 0,679 ) da palavra. Tasca (2006) considera que na posição final da palavra, mesmo o fonema /// sendo pronunciado como [w], há a possibilidade de sua preservação pelo fato de haver alternância com o som [l] em palavras cognatas, como, por exemplo, a palavra papel, pronunciada [pa'pew], que apresenta como cognatas as palavras papelaria, papelão, em que a letra <l> representa o som [l] e não [W]. Dessa forma, os dados da Tabela 4 comprovam que o contexto interno da sílaba se mostra mais favorável à vocalização de $<1>$ do que a posição final da sílaba, que tende a preservar a escrita da lateral.

Outra explicação para a posição final não ser favorecedora da vocalização é o fato de a maioria dos substantivos e adjetivos da nossa língua - classes gramaticais a que pertence grande parte das

7 Cf. nota 6. 
A variação da lateral pós-vocálica <।> na escrita de alunos: a posição da sílaba e a vogal precedente Laiane Thaís de Oliveira Silva • Josane Moreira de Oliveira

palavras do exercício -, mesmo apresentando a realização fonética [v] no final da palavra, não ser grafada com a vogal $\langle\mathrm{u}\rangle$, como em urso, cachorro, sozinho, lindo. Aqui fica evidente que os alunos já dominam a regra ortográfica segundo a qual se escrevem com a letra $<0>$ final palavras cuja pronúncia tem o som de [u].

Já com relação aos vocábulos monossilábicos, observa-se que também inibem a vocalização. Neste caso, entende-se que, como a escrita é uma convenção arbitrária e algumas regras necessitam de memorização, os vocábulos monossilábicos, por sua extensão, têm sua grafia mais rapidamente assimilada pelos alunos e, assim, há mais chance de serem escritos corretamente.

Alguns exemplos de dados do corpus analisado referentes ao grupo de fatores apresentado na Tabela 4 são os seguintes:

Posição inicial:

(15) aumoço ('almoço')

Posição medial:

(16) resouveu ('resolveu')

Posição final:

(17) caracou ('caracol')

Monossílabo:

(18) sou ('sol')

\subsection{Vogal precedente nos casos de vocalização com <u>}

Esta variável controla como a escrita da lateral $<1>$ se realiza após cada vogal. Os resultados referentes a este grupo de fatores podem ser visualizados na Tabela 5. Foram amalgamadas as vogais /e, $\varepsilon /$ e /o, o/ por se tratar de dados de língua escrita, em que são representadas com as mesmas letras, e por terem apresenta- 
A variação da lateral pós-vocálica <|> na escrita de alunos: a posição da sílaba e a vogal precedente Laiane Thaís de Oliveira Silva • Josane Moreira de Oliveira

do resultados estatísticos semelhantes quando consideradas separadamente as fechadas e as abertas, quando tônicas.

Tabela 5: Vocalização <u> e 'Vogal precedente'

\begin{tabular}{c|c|c|c}
\hline Vogal precedente & Ocorrências/total & Percentual & Peso relativo \\
\hline$A$ & $93 / 515$ & $18,1 \%$ & $\mathbf{0 , 5 6 7}$ \\
\hline$E$ & $87 / 438$ & $19,9 \%$ & $\mathbf{0 , 6 5 9}$ \\
\hline $\mathrm{I}$ & $72 / 539$ & $13,4 \%$ & $\mathbf{0 , 5 5 8}$ \\
\hline $\mathrm{O}$ & $86 / 438$ & $17,8 \%$ & $\mathbf{0 , 6 6 3}$ \\
\hline$U$ & $1 / 261$ & $0,4 \%$ & 0,033 \\
\hline
\end{tabular}

Input: 0,066 Significância: 0,007

Fonte: Silva (2020, p. 94).

O peso relativo para a vogal alta posterior $<u>(0,033)$ indica que esta inibe a vocalização devido, provavelmente, à impossibilidade de uma grafia $\langle\mathrm{u}\rangle+<\mathrm{u}\rangle$ (puuseira ou azuu). Como visto na seção 4.2, a vogal precedente <u> favorece o apagamento, com peso relativo de 0,886 . Pode-se inferir, então, que há uma distribuição complementar entre as regras de apagamento e vocalização. As demais vogais se mostraram favorecedoras da vocalização com $<u>$, com maiores índices para as vogais $<0>$ (peso relativo de 0,663 ) e <e $>$ (peso relativo de 0,659).

Abaixo seguem exemplos do corpus referentes à variável 'Vogal precedente'.

Vogal precedente A:

(19) aumoso ('almoço')

Vogal precedente E:

(20) seuva ('selva')

Vogal precedente I:

(21) fiume ('filme')

Vogal precedente O: 
A variação da lateral pós-vocálica <।> na escrita de alunos: a posição da sílaba e a vogal precedente Laiane Thaís de Oliveira Silva • Josane Moreira de Oliveira

(22) pouvo ('polvo')

Vogal precedente U:

(23) pounseria ('pulseira')

O exemplo (23), que corresponde ao único caso de vocalização com vogal precedente $<u>$ no corpus, foi assim interpretado porque o aluno utiliza a vogal <u> (caso que configura a vocalização) no lugar da consoante, considerando a estrutura da sílaba (CVC), em que aparece a lateral $<1>$.

Comparando o apagamento da lateral $<1>$ com a sua vocalização com <o>, constata-se que ambos ocorrem mais nas sílabas inicial e medial, mas o apagamento é favorecido quando a vogal que precede $<1>$ é $<0>$ ou $<u>$, enquanto esta última vogal é a única que inibe a vocalização.

\section{Considerações finais}

Esta pesquisa teve como objetivo investigar a variação na representação da consoante lateral pós-vocálica <l> na escrita de alunos dos $3^{\circ}$ e $5^{\circ}$ anos do Ensino Fundamental de duas escolas (uma pública e uma particular) da cidade de Riachão do Jacuípe-BA, verificando a atuação de duas variáveis: a 'posição da sílaba' e a 'vogal precedente'. As variantes consideradas neste artigo foram o apagamento da lateral <l> e a sua vocalização com <u>.

Os resultados obtidos confirmam, a respeito da variação na escrita da lateral $<\mid>$, que, devido ao seu caráter variável na oralidade, alunos em processo de aquisição da língua escrita, por não dominarem completamente as normas ortográficas, transpõem para a escrita fenômenos da fala. Mostram ainda que a posição da sílaba e a vogal precedente explicam algumas das razões pelas quais os alunos escolhem diferentes estratégias para representar graficamente a lateral $<1>$. 
A variação da lateral pós-vocálica <।> na escrita de alunos: a posição da sílaba e a vogal precedente Laiane Thaís de Oliveira Silva • Josane Moreira de Oliveira

Com relação ao apagamento do <1> na escrita, os resultados apontam que são os contextos de sílaba em posição medial e inicial da palavra, com pesos relativos de 0,947 e 0,814, respectivamente, que o favorecem, sendo, portanto, inibido em sílaba final de palavra (peso relativo de 0,190 ) pelo fato de possivelmente ser menos comum a pronúncia de palavras como [pa'pe] ('papel'), [a'nc] ('anel') pelos alunos, o que leva a ser mais comum a escrita de palavras como resoveu ('resolveu') e potrona ('poltrona') do que pape ('papel') e ane ('anel'), por exemplo. Os vocábulos monossilábicos tendem a preservar a grafia de $\langle 1>$, pois o peso relativo para o apagamento foi de apenas 0,140. Quanto à vogal precedente, favorecem o apagamento as vogais $\langle\mathrm{u}\rangle \mathrm{e}\langle 0\rangle$, com pesos relativos de 0,886 e 0,728, respectivamente, devido à pouca saliência fônica entre os sons de $\langle$ u $>$ e $<|>$ e $<0\rangle$ e $<1>$, se comparados com as demais vogais.

Os resultados encontrados para a variante vocalização com $<\mathrm{u}>$ mostram que são as sílabas inicial e medial as favorecedoras, com pesos relativos de 0,683 e 0,679, respectivamente, demonstrando que o contexto de sílaba interna é mais favorável à vocalização do $<>$ do que o de sílaba final (peso relativo de 0,410 ), que tende a preservar a escrita da lateral. Já com relação aos vocábulos monossilábicos, observa-se que estes também inibem a vocalização (peso relativo de 0,068), como também inibem o apagamento, e preservam $0<1>$. Quanto à variável vogal precedente, os resultados revelam que a vogal alta posterior $<u>$ é a única que inibe a vocalização (com peso relativo de 0,033 ) devido, provavelmente, à impossibilidade de uma grafia $<\mathrm{u}>+<\mathrm{u}>$ (puuseira ou azuu). Complementarmente, é essa vogal a que mais favorece o apagamento de $<1>$.

Os resultados sobre a variação na escrita da lateral /// em posição pós-vocálica podem indicar uma evidência empírica de que as variações ocorridas na língua (neste caso, na língua escrita) não são realizações que acontecem aleatoriamente, mas, pelo contrário, estão associadas a diversos fatores, inclusive de ordem linguística, como apresentado neste artigo. 
A variação da lateral pós-vocálica <।> na escrita de alunos: a posição da sílaba e a vogal precedente Laiane Thaís de Oliveira Silva • Josane Moreira de Oliveira

Os resultados de pesquisas como esta podem ainda contribuir para a pedagogia de professores das séries iniciais, a fim de que eles reconheçam as variações linguísticas ocorridas também na língua escrita - e decorrentes de interferências da oralidade e de desconhecimento das normas ortográficas - e possam tratá-las de forma adequada, bem como buscar caminhos que facilitem a superação de dificuldades na sala de aula. É preciso ainda lembrar que o aluno erra tentando acertar, pois há várias formas de se grafar o mesmo som. Assim como se escreve com <s> ou com <z> o som /z/ (Ásia, azia), só para exemplificar, escreve-se com <l> ou com <u> o som /w/: mel, meu; mal, mau; solto, Souto; vil, viu. Como as normas ortográficas são, às vezes, arbitrárias na sincronia, pois são baseadas na etimologia e/ou em pronúncias pretéritas, resta aos aprendizes da escrita lançar mão de hipóteses, em geral válidas, dentre as possibilidades que a língua oferece.

Finalmente, ressalta-se que a sociolinguística tem muito a contribuir para o ensino da língua materna, revelando a diversidade linguística, a sistematicidade da variação, a relação entre fala e escrita, e estimulando a prática do ativismo sociolinguístico (LABOV, 1972) nas salas de aula e na sociedade em geral, sobretudo com o combate ao preconceito linguístico e com o respeito às diferenças.

\section{Referências}

BORTONI-RICARDO, Stella Maris. Educação em língua materna: a sociolinguística na sala de aula. São Paulo: Parábola Editorial, 2004.

BRASIL. Parâmetros Curriculares Nacionais: língua portuguesa. Brasília: MEC/Secretaria de Educação Fundamental, 1997.

COELHO, Izete Lehmkuhl et al. Para conhecer sociolinguística. São Paulo: Contexto, 2015.

CRISTÓFARO SILVA, Thaïs. Fonética e fonologia do português: roteiro de estudos e guia de exercícios. São Paulo: Contexto, 1999. 
A variação da lateral pós-vocálica <|> na escrita de alunos: a posição da sílaba e a vogal precedente Laiane Thaís de Oliveira Silva • Josane Moreira de Oliveira

CYRANKA, Lúcia. Avaliação das variantes: atitudes e crenças em sala de aula. In: MARTINS, Marco Antônio; VIEIRA, Sílvia Rodrigues; TAVARES, Maria Alice (orgs.). Ensino de português e sociolinguística. São Paulo: Contexto, 2014, p. 133-155.

LABOV, William. Language in the Inner City: studies in the Black English vernacular. Pennsylvania: University of Pennsylvania Press, 1972.

LABOV, William. Padrões sociolinguísticos. Trad. de Marcos Bagno, Maria Marta Pereira Scherre e Caroline Rodrigues Cardoso. São Paulo: Parábola Editorial, 2008 [1972].

SILVA, Thaïs Crristófaro. Fonética e fonologia do português: roteiro de estudos e guia de exercícios. $4^{\text {a }}$ ed. São Paulo: Contexto, 2001. SILVA, Laiane Thaís de Oliveira. A variação da lateral pós-vocálica $<$ l> na escrita de alunos do $3^{\circ}$ e do $5^{\circ}$ anos do Ensino Fundamental. 2020. 145f. Dissertação (Mestrado em Estudos Linguísticos) Universidade Estadual de Feira de Santana, 2020.

TASCA, Maria. A presença da variação do segmento lateral na escrita das séries iniciais. In: GÖRSKI, Edair Maria; COELHO, Izete LehmkuhI (orgs.). Sociolinguística e ensino: contribuições para a formação do professor de língua. Florianópolis: UFSC, 2006. p. 185-207.

SANKOFF, David; TAGLIAMONTE, Sali; SMITH, Eric. GoldVarb X - a multivariate analysis application. Toronto: Department of Linguistics; Ottawa: Department of Mathematics, 2005.

WEINREICH, Uriel; LABOV, William; HERZOG, Marvin. Fundamentos empíricos para uma teoria da mudança linguística. Trad. de Marcos Bagno. São Paulo: Parábola Editorial, 2006 [1968]. 